\title{
Regular Practice of Competitive Sports Does Not Impair Sleep in Adolescents: DADOS Study
}

\author{
María Reyes Beltran-Valls \\ University Jaume I \\ Enrique García Artero \\ University of Almería \\ Ana Capdevila-Seder \\ University Jaume I \\ Alejandro Legaz-Arrese \\ University of Zaragoza

\begin{abstract}
Mireia Adelantado-Renau and Diego Moliner-Urdiales
University Jaume I
\end{abstract}

\begin{abstract}
Purpose: To analyze differences in sleep quality and duration by athletic status and sex, and to examine the association between physical activity (PA) recommendation and sleep in adolescents. Methods: A total of 267 adolescents [13.9 (0.3) y] from Deporte, ADOlescencia y Salud (DADOS) study (129 girls) were included in this cross-sectional analysis. Athletes competed regularly in organized sport events and trained $\geq 3$ days per week, but nonathletes did not compete. PA was assessed by GENEActiv accelerometer. PA values were dichotomized into inactive ( $<60 \mathrm{~min} / \mathrm{d}$ of moderate and vigorous PA) and active ( $\geq 60 \mathrm{~min} / \mathrm{d}$ of moderate and vigorous PA). Sleep quality was evaluated with the Spanish version of the Pittsburgh Sleep Quality Index. Pittsburgh Sleep Quality Index values were dichotomized into $>5$ (poor quality) or $\leq 5$ (good quality). Sleep duration was objectively measured by accelerometer. Results: Sleep quality and duration were not statistically different between athletes [median $(\mathrm{Mdn})=4.0$, interquartile range $(\mathrm{IQR})=3.0-6.0$ and $\mathrm{Mdn}=8.0, \mathrm{IQR}=7.4-8.6 \mathrm{~h}$, respectively] and nonathletes $(\mathrm{Mdn}=5.0, \mathrm{IQR}=3.0-7.0$ and $\mathrm{Mdn}=7.9$; IQR $=7.3-8.6 \mathrm{~h}$, respectively), $P>.05$. Nonathlete or inactive adolescents did not show higher risk for poor sleep quality or short sleep duration than athletes [odds ratio $(\mathrm{OR})=1.17 ; 95 \%$ confidence interval $(\mathrm{CI}), 0.68-2.00$ and $\mathrm{OR}=0.93 ; 95 \% \mathrm{CI}, 0.56-1.55$, respectively $]$ or active peers $(\mathrm{OR}=1.39 ; 95 \% \mathrm{CI}, 0.66-2.89$ and $\mathrm{OR}=1.62$; 95\% CI, 0.78-3.37, respectively). Conclusions: In our group of adolescents, competitive sport practice did not alter sleep patterns. PA recommendations for adolescents may not discriminate between good and poor sleepers.
\end{abstract}

Keywords: adolescence, health, athlete, physical activity

Adolescence is a crucial period of life characterized by several psychological and physiological changes (8)

\footnotetext{
Beltran-Valls, Capdevila-Seder, Adelantado-Renau, and MolinerUrdiales are with the LIFE Research Group, Dept. of Education, University Jaume I, Castellon, Spain. Artero is with the SPORT Research Group (CTS-1024), CERNEP Research Center, University of Almería, Almería, Spain; and Dept. of Education, Faculty of Education Sciences, University of Almería, Almería, Spain. Legaz-Arrese is with the Section of Physical Education and Sports, University of Zaragoza, Zaragoza, Spain. Address author correspondence to Diego Moliner-Urdiales at dmoliner@uji.es.
}

and by the establishment of many health-related behaviors such as sleep (9). Adequate sleep is considered a key health factor being particularly important for optimal physical, cognitive, and emotional development during childhood and adolescence (45). Although sleep research is mostly focused on duration, sleep quality is showing even more significant health-related consequences $(16,39)$.

Despite individual variations (31), the current sleep recommendation for adolescents is 8-10 hours of sleep per night (19). During adolescence, sleep duration and 
quality decrease, whereas sleep disturbances increase $(24,27,40)$, female adolescents being more affected than male adolescents $(4-6,24)$. These changes could lead to an increased risk of obesity (12), cardiometabolic risk (20), psychosocial disorders $(13,18)$, and cognitive disturbances (28). In addition, insufficient or disturbed sleep in adolescent athletes may influence exercise recovery, performance, and injury risk $(34,44)$.

Physical activity (PA) has been suggested to have a positive impact on sleep, improving duration and quality (23). Organized sport, which includes regular training sessions and competitions under coach supervision, is the most common practice of PA among children and adolescents (10). Recent research has highlighted the positive influence of general PA on sleep in young adults (14) and adolescents $(4,5,25)$. However, young adult athletes have reported to experience poor sleep $(26,46)$, but data on adolescent athletes are scarce and not conclusive $(3,4)$.

The primary aim of this study was to analyze the differences in sleep quality and duration between athlete and nonathlete adolescents. Secondary aims were to investigate sex differences in these sleep parameters and to examine whether meeting current daily PA recommendations was related to sleep.

The following hypotheses were investigated:

1) Even though general PA has been favorably related to adolescents' sleep, young adults participating in competitive sports reported more sleep disturbances than nonathletes $(26,46)$. Therefore, we expected to find poorer and shorter sleep among the athletes compared with nonathletes.

2) As previous data suggested higher sleep disturbances in female adolescents $(4-6,24)$, we expected to find poorer and shorter sleep in our group of females compared with males.

3) In line with the previous research (29), we expected to find that meeting current PA recommendation for adolescents would be positively associated to sleep patterns.

\section{Methods}

\section{Study Design and Participants}

This study is part of the Deporte, ADOlescencia y Salud (DADOS) research project, a 3-year longitudinal study aimed to analyze the influence of competitive PA on health, cognition, and psychological wellness through adolescence. All participants were recruited from secondary schools and sport clubs and met the general DADOS inclusion criteria (born in 2001, enrolled in second grade of secondary school, free of any chronic disease, regularly compete in organized sport events with at least 3 training sessions per week or not regularly compete in organized sport events). The results presented in this study belong to baseline data obtained between February and May of 2015.
A total of 267 adolescents (170 athletes and 97 nonathletes) completed the baseline assessment with valid data for sleep, body composition, and accelerometry. Two questions were used to classify the participants: "Are you competing regularly in organized sport events?" and "If you are regularly competing, how many training sessions do you perform per week?" Athletes were defined as adolescents who regularly compete in organized sport events with at least 3 training sessions per week. Nonathletes were defined as adolescents who did not regularly compete in organized sport events.

After receiving complete information about the aims and methods of the study, all adolescents and their parents or guardians included in the study signed the informed written consent. The study was performed following the ethical guidelines of the Declaration of Helsinki 1961 (revision of Fortaleza 2013), and the study protocol was approved by the research ethics committee of the University Jaume I.

\section{PA Measurement}

Participants' PA level was objectively measured using the GENEActiv accelerometer (Activinsights Ltd, Kimbolton, UK), a device that contains a triaxial microelectromechanical accelerometer that records both motion-related and gravitational acceleration and has a linear and equal sensitivity along the 3 axes. Participants wore the accelerometer on their nondominant wrist for at least 4 consecutive 24-hour days, including weekends and weekdays. This device has been found to be a reliable (coefficient of variation intrainstrument $=1.4 \%$ and coefficient of variation interinstrument $=2.1 \%$ ) (11) and valid objective measure of PA in young people $(r=.925, P=.001)$ (38). Accelerometers were programmed to collect data at a sampling frequency of $100 \mathrm{~Hz}$. Data were stored in gravity $(g)$ units $(1 g=$ $\left.9.81 \mathrm{~m} / \mathrm{s}^{2}\right)$. The raw acceleration output was converted to 1 -second epochs using the GENEActiv postprocessing PC software (version 2.2; GENEActiv). By combining all registered days for each participant and using the Excel macro provided by the commercial brand to summarize the data, PA was expressed as average minutes per day in sedentary, light, moderate, and vigorous PA. According to Phillips et al (38), GENEActiv cut points for sedentary, light, moderate, and vigorous intensities in children are <7, 7-19, 20-60, and $>60 \mathrm{~g}$. Moderate and vigorous PA (MVPA) was calculated by adding moderate PA and vigorous PA. Participants were categorized based on their daily MVPA level in active ( $\geq 60 \mathrm{~min} / \mathrm{d}$ of MVPA) or inactive ( $<60 \mathrm{~min} / \mathrm{d}$ of MVPA) in line with the general PA guidelines for adolescents proposed by the World Health Organization (49).

\section{Sleep Quality and Duration}

The Spanish version of Pittsburgh Sleep Quality Index (PSQI) was used to assess adolescents' sleep quality 
over the last month (42). It includes 19 questions in 7 components of sleep quality: subjective sleep quality, sleep duration, sleep latency, habitual sleep efficiency, sleep disturbance, use of sleep medication, and daytime dysfunction. The 7 component scores are rated on a 3 -point ascending scale, with 0 points indicating ideal sleep quality and 3 points indicating poor sleep quality. The global score of the PSQI is the sum of all component scores. The minimum possible score is 0 , indicating ideal sleep quality, and the maximum possible score is 21 , indicating poor sleep quality. According to Buysse et al (7), the PSQI provides a sensitive measure to identify poor sleep quality if total PSQI score is $>5$, comparable to clinical and laboratory measures (such as polysomnography). Therefore, we defined participants with total scores of 5 and below as "good sleepers," and those with total scores of 6 and above were defined as "poor sleepers."

Daily sleep duration was objectively measured by GENEActiv accelerometer (Activinsights Ltd). It has been found reliable to examine sleep $[\kappa=.85(.06)]$ (48). Sleep duration was calculated by the algorithm included in the macro provided by the Activinsights company based on the sum of accelerations $(<7 g)$ and evaluating the 60 prevalues and postvalues (120 measurement points) (43). In addition, to assist differentiation from sedentary time, participants kept a sleep log of their sleep-wake schedule to check possible inconsistencies in the accelerometer data. We observed high level of agreement between the accelerometer and the participants' sleep log data. However, when the results were discrepant, the day was removed, yet guaranteeing a measurement of at least 4 complete days for all participants analyzed. By combining all registered days for each participant, sleep duration was then expressed as average hours per day. In agreement with the American Sleep Foundation, short sleep in adolescent population is defined as sleeping less than 8 hours per night (19).

\section{Physical Examination}

Pubertal status was assessed according to the standardized Tanner stages based on external primary and secondary sex characteristics. The degree of development was self-reported by the participants using standard pictures consistent with Tanner instructions (47). Two components were assessed: pubic hair growth for boys and girls, plus breast development in girls and genital development in boys. A 5-point maturity rating was used where stage 1 corresponds to the prepubertal state and stage 5 corresponds to mature state. The highest rating of the 2 components was used for data analyses.

Weight and height were obtained with the participant in light indoor clothes and without shoes by using standard procedures as in our previous study (36). Weight was measured with an electronic scale (model 861; seca, Hamburg, Germany) to the nearest $0.1 \mathrm{~kg}$. Height was measured in the Frankfort plane with a wall-mounted stadiometer (model 213; seca) to the nearest $0.1 \mathrm{~cm}$. Weight and height were measured in duplicate, and the average was used for data analyses. Body mass index was calculated as weight in kilograms divided by the square of the height in meters $\left(\mathrm{kg} / \mathrm{m}^{2}\right)$. In addition, 2 nonconsecutive measurements of waist circumference were performed at the thinnest waist diameter between the last rib bone and the superior iliac crest using a homologated flexible steel tape (Harpenden anthropometric tape; Holtain Ltd, Crymych, UK), and the average was used for data analyses. Skinfold thicknesses were measured at the left side of the body to the nearest $0.2 \mathrm{~mm}$ using a Holtain skinfold caliper at 2 sites (triceps and subscapular) following standardized procedures (36). Two measurements of each skinfold were performed, and the average value was used for data analyses.

\section{Statistical Analysis}

Continuous variables are presented as mean $(S D)$, and categorical variables are presented as absolute frequency and percentage. Normality of variables' distribution was tested by Kolmogorov-Smirnov test. One-way analysis of variance or Mann-Whitney $U$ test was used for comparisons between groups for normal and non-normal distributed variables, respectively. Differences between categorical variables were tested by chi-square test. Logistic regression models were used to assess odds ratio (OR) and 95\% confidence intervals (CIs) for poor sleep quality and short sleep duration according to athletic status and PA level, after adjusting for sex and pubertal status. The analyses were conducted in the total sample as sex interactions were not found between athletic status and sleep data. All the analyses were performed using the IBM SPSS Statistics for Windows (version 22.0; IBM Corp, Armonk, NY). Data are presented as mean $(S D)$, median $(\mathrm{Mdn})$, and the interquartile range (IQR) Q1 (25th)-Q3 (75th) or frequency, depending upon the type of data. The level of significance was set to $P<.05$.

\section{Results}

Descriptive characteristics of the study population are shown in Table 1. From the total sample, $72 \%$ of boys and $54 \%$ of girls were classified as an athlete $(P<.01)$. Boys were taller and showed higher values of waist circumference, whereas girls presented a higher body fat percentage (all $P \mathrm{~S}<.05$ ). PA data indicated that boys accumulated more daily minutes of moderate, vigorous, and MVPA than girls $(P<.001)$. Most of the boys and 7 out of 10 girls achieved daily PA recommendations $(P<.001)$. Boys scored lower (better) in PSQI index than girls $(P<.001)$. Higher proportions of poor sleep quality (46\% vs $26 \%)$ were identified among girls $(P<.001)$. Sleep duration results were similar between boys and girls $(P>.05)$.

Differences according to athletic status are shown in Table 2. Athletes presented a lower body fat percentage compared with nonathletes $(P<.05)$. Athletes achieved higher levels of PA at all intensities (all $P \mathrm{~s}<.05)$ and lower levels of sedentary time $(P<.01)$ than nonathletes. Sleep 
Table 1 Characteristics of the Study Population by Sex

\begin{tabular}{|c|c|c|c|c|}
\hline Variable & All $(N=267)$ & Boys $(n=138)$ & Girls $(n=129)$ & $P$ values \\
\hline Age, $y^{a}$ & $13.9(0.3)$ & $13.9(0.3)$ & $13.9(0.3)$ & .92 \\
\hline Tanner stage, $\mathrm{I}-\mathrm{V}^{\mathrm{c}}$ & $0 / 21 / 92 / 128 / 26$ & $0 / 14 / 45 / 59 / 20$ & $0 / 7 / 47 / 69 / 6$ & $<.05$ \\
\hline Athletes ${ }^{c}$ & $170(64)$ & $100(72)$ & $70(54)$ & $<.01$ \\
\hline Height, $\mathrm{cm}^{\mathrm{a}}$ & $163.0(7.9)$ & $164.7(8.6)$ & $161.2(6.7)$ & $<.001$ \\
\hline Weight, $\mathrm{kg}^{\mathrm{a}}$ & $54.0(9.1)$ & $54.5(9.6)$ & $53.5(8.6)$ & .38 \\
\hline BMI, $\mathrm{kg} / \mathrm{m}^{2 \mathrm{a}}$ & $20.3(2.7)$ & $20.0(2.5)$ & $20.5(2.8)$ & .09 \\
\hline Waist, $\mathrm{cm}^{\mathrm{a}}$ & $67.2(5.7)$ & $68.1(5.5)$ & $66.2(5.8)$ & $<.01$ \\
\hline Body fat, $\%^{\mathrm{a}}$ & $21.8(7.2)$ & $18.4(6.9)$ & $25.4(5.5)$ & $<.001$ \\
\hline Sedentary time, $\min / \mathrm{d}^{\mathrm{b}}$ & $702.5(662.9-741.1)$ & $709.3(662.8-747.8)$ & $691.5(663.1-736.1)$ & .29 \\
\hline Light $\mathrm{PA}, \min / \mathrm{d}^{\mathrm{b}}$ & $168.5(154.7-186.7)$ & $166.6(154.7-183.2)$ & $171.4(154.3-190.1)$ & .21 \\
\hline Moderate $\mathrm{PA}, \mathrm{min} / \mathrm{d}^{\mathrm{b}}$ & $74.9(59.7-87.7)$ & $79.8(64.2-93.5)$ & $69.4(56.3-81.5)$ & $<.001$ \\
\hline Vigorous PA, min/d & $10.6(6.1-17.3)$ & $15.2(9.2-20.3)$ & $6.8(3.4-11.3)$ & $<.001$ \\
\hline MVPA, $\min / \mathrm{d}^{\mathrm{b}}$ & $85.2(67.7-105.4)$ & $94.5(78.6-112.2)$ & $76.4(63.0-93.1)$ & $<.001$ \\
\hline $\mathrm{MVPA} \geq 60 \mathrm{~min} / \mathrm{d}^{\mathrm{c}}$ & $231(86)$ & $129(93)$ & $102(79)$ & $<.001$ \\
\hline PSQI, 0-21 ${ }^{\mathrm{b}}$ & $4.0(3.0-6.0)$ & $4.0(2.0-6.0)$ & $5.0(3.5-7.0)$ & $<.001$ \\
\hline Poor sleep quality ${ }^{\mathrm{c}}$ & $95(36)$ & $36(26)$ & $59(46)$ & $<.001$ \\
\hline Sleep duration, $\mathrm{h}^{\mathrm{b}}$ & $8.0(7.4-8.6)$ & $7.9(7.2-8.5)$ & $8.0(7.6-8.7)$ & .05 \\
\hline Short sleep duration ${ }^{c}$ & $134(50)$ & $73(53)$ & $61(47)$ & .36 \\
\hline
\end{tabular}

Note. Poor sleep quality indicates PSQI $>5$. Athletes indicate to play regular sport competitions and $\geq 3$ training sessions per week. Short sleep duration indicates $<8$ hours per night. Values in bold indicate statistically significant results $(P<.05)$.

Abbreviations: BMI, body mass index; MVPA, moderate and vigorous physical activity; PA, physical activity; PSQI, Pittsburgh Sleep Quality Index. ${ }^{\mathrm{a}}$ Data are presented as mean $(S D)$, and differences between boys and girls were examined by analysis of the variance.

${ }^{\mathrm{b}}$ Data are presented as median (25th-75th), and differences between boys and girls were examined by independent-samples Mann-Whitney $U$ test.

${ }^{\mathrm{c}}$ Data are presented as frequency $(\%)$, and differences between boys and girls were examined by independent-samples chi-square test.

quality and sleep duration did not show statistical differences between groups. Additional analyses by sex showed lower PSQI scores (better) in male athletes $(\mathrm{Mdn}=4.0$, $\mathrm{IQR}=2.0-5.0)$ than female athletes $(\mathrm{Mdn}=5.0, \mathrm{IQR}=$ $3.0-7.0 ; P<.01)$ and in male nonathletes $(\mathrm{Mdn}=3.0$, IQR $=2.0-6.0)$ than female nonathletes $(\mathrm{Mdn}=5.0, \mathrm{IQR}=3.2-$ $7.0 ; P<.01)$. Sleep duration did not show statistical differences between male athletes $(\mathrm{Mdn}=8.1, \mathrm{IQR}=7.3-8.6 \mathrm{~h})$ and female athletes $(\mathrm{Mdn}=7.9, \mathrm{IQR}=7.6-8.7 \mathrm{~h} ; P>.05)$, but male nonathletes $(\mathrm{Mdn}=7.6, \mathrm{IQR}=6.9-8.4 \mathrm{~h})$ slept shorter than female nonathletes $(\mathrm{Mdn}=8.2, \mathrm{IQR}=7.6$ 8.9 h; $P<.01)$.

Logistic regression models for sleep quality and sleep duration are shown in Table 3. According to athletic status, nonathlete adolescents did not show higher risk for poor sleep quality or short sleep duration $(\mathrm{OR}=1.17 ; 95 \% \mathrm{CI}, 0.68-2.00$ and $\mathrm{OR}=0.93 ; 95 \% \mathrm{CI}$, 0.56-1.55, respectively). Additional analyses based on PA levels revealed that inactive adolescents did not have higher risk for poor sleep quality or short duration $(\mathrm{OR}=$ 1.39 ; 95\% CI, 0.66-2.89 and OR $=1.62$; 95\% CI, 0.78 3.37, respectively).

\section{Discussion}

To our knowledge, this is the first study analyzing differences on sleep quality and sleep duration between athlete and nonathlete adolescents including also objectively measured PA. The main finding of this study was that adolescent athletes did not show poorer sleep quality or shorter sleep duration compared with nonathletes. We also found that adolescent females experience poorer sleep quality than males. Moreover, meeting daily PA recommendations was not related to sleep quality or duration in adolescents.

As regards sex-differences analyses, our results agree with previous studies showing poorer sleep quality in girls (4-6). The underlying reasons of these sex differences remain unclear, and based on our results, only speculative explanations can be given. A recent study analyzing sleep differences by sex (50) proposes that girls are more susceptible to emotional and behavioral problems. In addition, female adolescents experience higher internalization of problems than males $(2,5)$ and may be more concerned about being accepted by peers (17). Biological sex and sex steroids appear to have an important role both in the modulation of sleep and depressive symptoms $(1,35)$. In fact, ovarian steroids fluctuation occurring during different periods of life, such as puberty, has been found to increase sleep complaints (35). Therefore, these gender-specific psychological and physiological factors could make females more susceptible to experience sleep disturbances. In addition, the lower levels of PA observed in girls could also partially explain the sleep differences among sex groups. 
Table 2 Body Composition, PA, and Sleep Quality/Duration According to Athletic Status

\begin{tabular}{|c|c|c|c|}
\hline Variable & Athletes $(n=170)$ & Nonathletes $(n=97)$ & $P$ values \\
\hline BMI, $\mathrm{kg} / \mathrm{m}^{2 \mathrm{a}}$ & $20.2(2.4)$ & $20.4(3.1)$ & .56 \\
\hline Waist, $\mathrm{cm}^{\mathrm{a}}$ & $67.3(5.4)$ & $67.0(6.3)$ & .61 \\
\hline Body fat, $\%^{\mathrm{a}}$ & $20.8(6.4)$ & $23.6(8.1)$ & $<.01$ \\
\hline Sedentary time, $\min / \mathrm{d}^{\mathrm{b}}$ & $689.5(648.3-731.9)$ & $720.3(684.2-764.1)$ & $<.001$ \\
\hline Light PA, $\min / \mathrm{d}^{\mathrm{b}}$ & $171.5(156.2-189.3)$ & $163.8(150.4-180.7)$ & $<.05$ \\
\hline Moderate $\mathrm{PA}, \mathrm{min} / \mathrm{d}^{\mathrm{b}}$ & $79.8(67.2-92.3)$ & $61.6(52.2-78.1)$ & $<.001$ \\
\hline Vigorous $\mathrm{PA}, \mathrm{min} / \mathrm{d}^{\mathrm{b}}$ & $14.8(9.2-20.4)$ & $5.5(2.8-9.9)$ & $<.001$ \\
\hline $\mathrm{MVPA}, \mathrm{min} / \mathrm{d}^{\mathrm{b}}$ & $93.5(80.2-111.5)$ & $67.7(58.5-85.0)$ & $<.001$ \\
\hline PSQI, $0-21^{\mathrm{b}}$ & $4.0(3.0-6.0)$ & $5.0(3.0-7.0)$ & .42 \\
\hline Poor sleep quality ${ }^{\mathrm{c}}$ & $56(33)$ & $39(40)$ & .23 \\
\hline Sleep duration, $\mathrm{h}^{\mathrm{b}}$ & $8.0(7.4-8.6)$ & $7.9(7.3-8.6)$ & .83 \\
\hline Short sleep duration ${ }^{c}$ & $85(50)$ & $49(50)$ & .93 \\
\hline
\end{tabular}

Note. Poor sleep quality indicates PSQI $>5$. Short sleep duration indicates $<8$ hours per night. Athletes indicate to play regular sport competitions and $\geq 3$ training sessions per week. Values in bold indicate statistically significant results $(P<.05)$.

Abbreviations: BMI, body mass index; MVPA, moderate and vigorous physical activity; PA, physical activity; PSQI, Pittsburgh Sleep Quality Index. ${ }^{a}$ Data are presented as mean $(S D)$ and differences between athletes and nonathletes were examined by analysis of the variance.

${ }^{\mathrm{b}}$ Data are presented as median (25th-75th) and differences between athletes and nonathletes were examined by independent-samples Mann-Whitney $U$ test.

${ }^{\mathrm{c}}$ Data are presented as frequency $(\%)$ and differences between athletes and nonatheletes were examined by independent-samples chi-square test.

Table 3 Logistic Regression Models for Poor Sleep Quality and Duration According to Athletic Status and PA Level

\begin{tabular}{|c|c|c|c|c|c|}
\hline & \multirow[b]{2}{*}{$n(\%)$} & \multicolumn{2}{|c|}{ Sleep quality } & \multicolumn{2}{|c|}{ Sleep duration } \\
\hline & & OR & $95 \% \mathrm{Cl}$ & OR & $95 \% \mathrm{Cl}$ \\
\hline \multicolumn{6}{|l|}{ Athletic status } \\
\hline athletes & $170(64)$ & 1 & Reference & 1 & Reference \\
\hline nonathletes & $97(36)$ & 1.17 & $0.68-2.00$ & 0.93 & $0.56-1.55$ \\
\hline \multicolumn{6}{|c|}{ Physical activity } \\
\hline active & $231(86)$ & 1 & Reference & 1 & Reference \\
\hline inactive & $36(14)$ & 1.39 & $0.66-2.89$ & 1.62 & $0.78-3.37$ \\
\hline
\end{tabular}

Note. Analyses were sex- and pubertal status-adjusted. Athletes indicate to play regular sport competitions and $\geq 3$ training sessions per week. Active indicates $\geq 60$ minutes per day MVPA.

Abbreviations: CI, confidence interval; MVPA, moderate and vigorous physical activity; OR, odds ratio; PA, physical activity.

The association between sleep patterns and health status during adolescence is well established (45), but the influence of high-level sport practice on sleep remains to be better elucidated. In agreement with previous research $(15,21,37)$, around $40 \%$ of our adolescents showed poor sleep quality, and sleep duration was slightly below the average of European adolescents. However, our data did not show any statistical difference on sleep quality or sleep duration according to athletic status. The logistic regression analyses showed that nonathletes and inactive adolescents did not have higher risk for poor sleep quality or short sleep duration, independently of sex and pubertal status. To our knowledge, this is the first study in performing a predictive analysis to investigate the likelihood of sleep disorders (poor sleep quality and short sleep duration) based on athletic status or PA recommendation achievement.
Previous studies showed that adolescent athletes achieving high levels of PA reported more favorable sleep patterns compared with nonathlete healthy controls $(3,4,37)$. In contrast, more awakenings and less sleep efficiency have been reported in young adult elite athletes $(26,41,46)$. Athletes' training schedule and competitions could increase psychosocial and physiological stress, which has been related with poorer sleep quality in adults (32). Nevertheless, high-intensity exercise has also been related to lower stress and increased mental health in young adults $(14,22)$ and adolescents $(4,5)$. Dealing successfully with the psychological and physiological sport-related demands is highly individualistic and might be influenced by the deep changes occurring during adolescence (8), so its impact on sleep might be different between participants. In our study, a possible effect of the sports participation requirements on sleep 
patterns may have been minimized by the individual coping strategies adopted by adolescents (30). Therefore, the heterogeneity of the analyzed samples together with the methodological differences among studies could partially explain the controversial results found regarding sports practice and sleep patterns.

Current recommendation of PA for adolescents (at least $60 \mathrm{~min} / \mathrm{d}$ of MVPA) is associated with a high number of physical and psychological health benefits (49). Nevertheless, based on objective PA assessment carried out in our study, this recommendation is not related with sleep quality or duration in healthy adolescents. Conversely, in a vast group of adults from 18 to 85 years, meeting PA recommendation was associated with a lower risk of feeling sleepy during the day (29). It could be possible that a different amount and/or intensity of PA, higher than 60 minutes per day of MVPA, is needed to affect sleep patterns in adolescents.

The results of this study should be interpreted with caution due to several limitations. First, the direction of causality between PA and sleep patterns cannot be determined due to the cross-sectional design of the study. Second, our nonathlete group was considered on average physically active according to the PA recommendations for adolescents. Due to the voluntary participation in the study, the nonathletes included in this group may be more favorable toward being physically active than other peers. For that reason, they may not be representative of the general adolescent population, as $62.6 \%$ of Spanish adolescents do not meet the PA recommendations (33). Therefore, the lack of significant findings could be related to the fact that the nonathletes group was not considered physically inactive. Third, we did not consider other potential confounders in the analyses such as training schedule or caffeine consumption. Despite these limitations, the main strengths of our study include a homogenous sample of adolescents in terms of age and sex with different competitive sport participation and PA levels assessed objectively by accelerometry.

In conclusion, the findings of this study add new information about the relationship between PA and sleep in adolescents, indicating that high-level sport practice did not affect sleep patterns in our sample. In addition, our data suggest that current PA recommendations for adolescents may not discriminate between good and poor sleepers. Parents, coaches, and educators should consider our data to promote regular PA and competitive sports for children and adolescents for general health and sleep as they do not seem to be detrimental for sleep quality and duration. Further longitudinal and interventional studies examining the relationship between PA and sleep are still needed.

\section{Acknowledgments}

DADOS study is funded by the Spanish Ministry of Economy and Competitiveness (MINECO; DEP2013-45515-R). This work is partly supported by a Sunny Sport Research Grant from the Schweppes Suntory Spain Company. E.G.A. was supported by a
Ramón y Cajal Research Grant from MINECO (RYC-201416390). M.A.R. is supported by a Predoctoral Research Grant from University Jaume I (PREDOC/2015/13). The content is solely the responsibility of the authors and does not necessarily represent the official views of the funding institutions.

\section{References}

1. Armitage R, Hoffmann RF. Sleep EEG, depression and gender. Sleep Med Rev. 2001;5(3):237-46. doi:10.1053/ smrv.2000.0144

2. Bor W, Dean AJ, Najman J, Hayatbakhsh R. Are child and adolescent mental health problems increasing in the $21 \mathrm{st}$ century? A systematic review. Aust N Z J Psychiatry. 2014;48(7):606-16. doi:10.1177/0004867414533834

3. Brand S, Beck J, Gerber M, Hatzinger M, HolsboerTrachsler E. "Football Is Good for Your Sleep": favorable sleep patterns and psychological functioning of adolescent male intense football players compared to controls. J Health Psychol. 2009;14(8):1144-55. doi:10.1177/ 1359105309342602

4. Brand S, Gerber M, Beck J, Hatzinger M, Pühse U, Holsboer-Trachsler E. High exercise levels are related to favorable sleep patterns and psychological functioning in adolescents: a comparison of athletes and controls. $J$ Adolesc Health. 2010;46(2):133-41. PubMed doi:10. 1016/j.jadohealth.2009.06.018

5. Brand S, Kalak N, Gerber M, et al. During early to mid adolescence, moderate to vigorous physical activity is associated with restoring sleep, psychological functioning, mental toughness and male gender. J Sports Sci. 2017;35(5):426-34. PubMed doi:10.1080/02640414. 2016.1167936

6. Brand S, Kirov R, Kalak N, et al. Poor sleep is related to lower emotional competence among adolescents. Behav Sleep Med. 2016;14(6):602-14. PubMed doi:10.1080/ 15402002.2015.1048450

7. Buysse DJ, Reynolds CF, Monk TH, Berman SR, Kupfer DJ. The Pittsburgh Sleep Quality Index: a new instrument for psychiatric practice and research. Psychiatry Res. 1989;28(2):193-213. PubMed doi:10.1016/0165-1781 (89)90047-4

8. Casey BJ, Jones RM, Levita L, et al. The storm and stress of adolescence: insights from human imaging and mouse genetics. Dev Psychobiol. 2010;52(3):225-35. PubMed doi:10.1002/dev.20447

9. Dregan A, Armstrong D. Adolescence sleep disturbances as predictors of adulthood sleep disturbances-a cohort study. J Adolesc Health. 2010;46(5):482-7. PubMed doi:10.1016/j.jadohealth.2009.11.197

10. Eime RM, Harvey JT, Charity MJ, Casey MM, Westerbeek H, Payne WR. Age profiles of sport participants. BMC Sports Sci Med Rehabil. 2016;8(6):1-10. PubMed doi:10.1186/s13102-016-0031-3

11. Esliger DW, Rowlands AV, Hurst TL, Catt M, Murray P, Eston RG. Validation of the GENEA accelerometer. Med Sci Sports Exerc. 2011;43(6):1085-93. PubMed doi:10. 1249/MSS.0b013e31820513be 
12. Fatima Y, Doi SA, Mamun AA. Longitudinal impact of sleep on overweight and obesity in children and adolescents: a systematic review and bias-adjusted meta-analysis. Obes Rev. 2015;16(2):137-49. doi:10.1111/obr.12245

13. Fuligni AJ, Hardway C. Daily variation in adolescents' sleep, activities, and psychological well-being. $J$ Res Adolesc. 2006;16(3):353-78. doi:10.1111/j.1532-7795.2006.00498.x

14. Gerber M, Brand S, Herrmann C, Colledge F, HolsboerTrachsler E, Pühse U. Increased objectively assessed vigorous-intensity exercise is associated with reduced stress, increased mental health and good objective and subjective sleep in young adults. Physiol Behav. 2014; 135:17-24. PubMed doi:10.1016/j.physbeh.2014.05.047

15. Gradisar M, Gardner G, Dohnt H. Recent worldwide sleep patterns and problems during adolescence: a review and meta-analysis of age, region, and sleep. Sleep Med. 2011; 12(2):110-8. PubMed doi:10.1016/j.sleep.2010.11.008

16. Gruber R, Somerville G, Enros P, Paquin S, Kestler M, Gillies-Poitras E. Sleep efficiency (but not sleep duration) of healthy school-age children is associated with grades in math and languages. Sleep Med. 2014;15(12):1517-25. PubMed doi:10.1016/j.sleep.2014.08.009

17. Guyer AE, Caouette JD, Lee CC, Ruiz SK. Will they like me? Adolescents' emotional responses to peer evaluation. Int J Behav Dev. 2014;38(2):155-63. PubMed doi:10. 1177/0165025413515627

18. Harris A, Gundersen H, Andreassen PM, Thun E, Bjorvatn $B$, Pallesen S. A comparative study of sleep and mood between young elite athletes and age-matched controls. $J$ Phys Act Health. 2017;14(6):465-73. PubMed doi:10.1123/jpah.2016-0513

19. Hirshkowitz M, Whiton K, Albert SM, et al. National Sleep Foundation's sleep time duration recommendations: methodology and results summary. Sleep Health. 2015;1(1):40-3. doi:10.1016/j.sleh.2014.12.010

20. Hjorth MF, Chaput JP, Damsgaard CT, et al. Low physical activity level and short sleep duration are associated with an increased cardio-metabolic risk profile: a longitudinal study in 8-11 year old danish children. PLOS ONE. 2014;9(8):e104677. PubMed doi:10.1371/journal.pone. 0104677

21. Hysing M, Pallesen S, Stormark KM, Lundervold AJ, Sivertsen B. Sleep patterns and insomnia among adolescents: a population-based study. J Sleep Res. 2013; 22(5):549-56. PubMed doi:10.1111/jsr.12055

22. Kalak N, Gerber M, Kirov R, et al. Daily morning running for 3 weeks improved sleep and psychological functioning in healthy adolescents compared with controls. $J$ Adolesc Health. 2012;51(6):615-22. PubMed doi:10. 1016/j.jadohealth.2012.02.020

23. Kredlow MA, Capozzoli MC, Hearon BA, Calkins AW, Otto MW. The effects of physical activity on sleep: a meta-analytic review. J Behav Med. 2015;38(3):427-49. doi:10.1007/s10865-015-9617-6

24. Kronholm E, Puusniekka R, Jokela J, et al. Trends in selfreported sleep problems, tiredness and related school performance among Finnish adolescents from 1984 to 2011. J Sleep Res. 2015;24(1):3-10. PubMed doi:10. 1111 jsr. 12258
25. Lang C, Brand S, Feldmeth AK, Holsboer-Trachsler E, Pühse U, Gerber M. Increased self-reported and objectively assessed physical activity predict sleep quality among adolescents. Physiol Behav. 2013;120:46-53. doi:10.1016/j.physbeh.2013.07.001

26. Leeder J, Glaister M, Pizzoferro K, Dawson J, Pedlar C. Sleep duration and quality in elite athletes measured using wristwatch actigraphy. J Sports Sci. 2012;30(6):541-5. doi:10.1080/02640414.2012.660188

27. Leger D, Beck F, Richard JB, Godeau E. Total sleep time severely drops during adolescence. PLOS ONE. 2012;7(10):e45204. PubMed doi:10.1371/journal.pone. 0045204

28. Lo JC, Ong JL, Leong RLF, Gooley JJ, Chee MW. Cognitive performance, sleepiness, and mood in partially sleep deprived adolescents: the need for sleep study. Sleep. 2016;39(3):687-98. doi:10.5665/sleep.5552

29. Loprinzi PD, Cardinal BJ. Association between objectively-measured physical activity and sleep, NHANES 2005-2006. Ment Health Phys Act. 2011;4(2):65-9. doi:10.1016/j.mhpa.2011.08.001

30. Matthews KA, Hall MH, Cousins J, Lee L. Getting a good night's sleep in adolescence: do strategies for coping with stress matter? Behav Sleep Med. 2016;14(4):367-77. doi:10.1080/15402002.2015.1007994

31. Mercer PW, Merritt SL, Cowell JM. Differences in reported sleep need among adolescents. J Adolesc Health. 1998;23 (5):259-63. doi:10.1016/S1054-139X(98)00037-8

32. Mezick EJ, Matthews KA, Hall M, et al. Intra-individual variability in sleep duration and fragmentation: associations with stress. Psychoneuroendocrinology. 2009; 34(9):1346-54. doi:10.1016/j.psyneuen.2009.04.005

33. Mielgo-Ayuso J, Aparicio-Ugarriza R, Castillo A, et al. Physical activity patterns of the Spanish population are mostly determined by sex and age: findings in the ANIBES study. PLoS ONE. 2016;11(2):e0149969. PubMed doi:10.1371/journal.pone.0149969

34. Milewski MD, Skaggs DL, Bishop GA, et al. Chronic lack of sleep is associated with increased sports injuries in adolescent athletes. J Pediatr Orthop. 2014;34(2):12933. PubMed doi:10.1097/BPO.0000000000000151

35. Mong JA, Cusmano DM. Sex differences in sleep: impact of biological sex and sex steroids. Philos Trans $R$ Soc B Biol Sci. 2016;371(1688):20150110. PubMed doi:10. 1098/rstb.2015.0110

36. Nagy E, Vicente-Rodriguez G, Manios Y, et al. Harmonization process and reliability assessment of anthropometric measurements in a multicenter study in adolescents. Int J Obes. 2008;32 Suppl 5:S58-65. PubMed doi:10.1038/ijo.2008.184

37. Ortega FB, Chillón P, Ruiz JR, et al. Sleep patterns in Spanish adolescents: associations with TV watching and leisure-time physical activity. Eur J Appl Physiol. 2010;110(3):563-73. PubMed doi:10.1007/s00421-0101536-1

38. Phillips LRS, Parfitt G, Rowlands AV. Calibration of the GENEA accelerometer for assessment of physical activity intensity in children. $J$ Sci Med Sport. 2013;16(2):124-8. PubMed doi:10.1016/j.jsams.2012.05.013 
39. Pilcher JJ, Ginter DR, Sadowsky B. Sleep quality versus sleep quantity: relationships between sleep and measures of health, well-being and sleepiness in college students. $J$ Psychosom Res. 1997;42(6):583-96. PubMed doi:10. 1016/S0022-3999(97)00004-4

40. Roberts RE, Roberts CR, Duong HT. Chronic insomnia and its negative consequences for health and functioning of adolescents: a 12-month prospective study. J Adolesc Health. 2008;42(3):294-302. doi:10.1016/j.jadohealth.2007.09.016

41. Robey E, Dawson B, Halson S, Gregson W, Goodman C, Eastwood P. Sleep quantity and quality in elite youth soccer players: a pilot study. Eur J Sport Sci. 2014;14 (5):410-7. doi:10.1080/17461391.2013.843024

42. Royuela Rico A, Macías Fernánedez JA. Propiedades clinimétricas de la versión castellana del cuestionario de Pittsburgh. Vigilia-Sueño. 1997;9(2):81-94.

43. Sadeh A, Sharkey KM, Carskadon MA. Activity-based sleep-wake identification: an empirical test of methodological issues. Sleep. 1994;17(3):201-7.

44. Samuels C. Sleep, recovery, and performance: the new frontier in high-performance athletics. Neurol Clin. 2008;26(1):169-80. doi:10.1016/j.ncl.2007.11.012
45. Shochat T, Cohen-Zion M, Tzischinsky O. Functional consequences of inadequate sleep in adolescents: a systematic review. Sleep Med Rev. 2014;18(1):75-87. PubMed doi:10.1016/j.smrv.2013.03.005

46. Swinbourne R, Gill N, Vaile J, Smart D. Prevalence of poor sleep quality, sleepiness and obstructive sleep apnoea risk factors in athletes. Eur J Sport Sci. 2016;16 (7):850-8. doi:10.1080/17461391.2015.1120781

47. Tanner J. Growth at Adolescence. 2nd ed. Oxford, UK: Blackwell; 1962.

48. Te Lindert BHW, Van Someren EJW. Sleep estimates using microelectromechanical systems (MEMS). Sleep. 2013;36(5):781-9. doi:10.5665/sleep.2648

49. World Health Organization. Global Recommendations on Physical Activity for Health. Geneva Switzerland: World Health Organization; 2010. Available from: http://apps. who.int/iris/bitstream/10665/44399/1/9789241599979_ eng.pdf.

50. Zhang J, Chan NY, Lam SP, et al. Emergence of sex differences in insomnia symptoms in adolescents: a largescale school-based study. Sleep. 2016;39(8):1563-70. PubMed doi:10.5665/sleep.6022 